\title{
DO CURSO PLANEJADO AO VIVENCIADO NO PROEJA DO IFMT - CAMPUS VÁRZEA GRANDE: AVANÇOS, DESAFIOS E DIFICULDADES
}

\author{
Sônia Maria de Almeida ${ }^{1}$ \\ Maria Emília de Castro Rodrigues ${ }^{2}$
}

\section{Resumo}

Este estudo teve como objetivo compreender a experiência do Curso Técnico em Serviços de Condomínio - Proeja do IFMT Campus Várzea Grande, a partir da escuta dos professores, revelando elementos que contribuíram para a permanência/náo permanência dos educandos do curso. Pelo recorte que fizemos, norteamos a observação da prática pedagógica do professor com base nas concepçôes e princípios definidos no Documento Base (2007), estabelecendo o confronto entre o discurso presente nas entrevistas dos professores pesquisados, o definido no documento e o que realmente pode ser constatado em sala de aula. A coleta de dados se deu pela revisão bibliográfica, questionário, entrevistas, análise documental e observação em sala de aula, e a metodologia foi o estudo de caso. Os resultados evidenciaram lacunas em relação à oferta do Proeja no campus que não se resumem apenas às práticas pedagógicas dos professores, que também contribuíram para o fechamento do curso. A prática pedagógica observada nos trouxe elementos para pensar sobre o processo educativo, com foco na educação do trabalhador para o mundo do trabalho.

Palavras-chave: Prática pedagógica. Proeja. Currículo Integrado.

1 Mestra em Educação, pedagoga do Instituto Federal de Educação, Ciência e Tecnologia de Mato Grosso - Campus Várzea Grande. E-mail: sonia.almeida@vgd.ifmt.edu.br

2 Doutora em Educação, professora aposentada da Universidade Federal de Goiás. E-mail: me.castrorodrigues@gmail.com 


\section{Introdução}

Este artigo é um recorte da pesquisa do Mestrado Interinstitucional entre o Programa de Pós-Graduação em Educação da Faculdade de Educação da Universidade Federal de Goiás e o Instituto Federal de Educação, Ciência e Tecnologia de Mato Grosso - IFMT, intitulada (Re)pensando o Proeja no Instituto Federal de Educação, Ciência e Tecnologia de Mato Grosso (IFMT) Campus Várzea Grande a partir do olhar do(s) professor(es), inserida na linha de pesquisa Educação, trabalho e movimentos sociais, vinculada à pesquisa Desafios da Educação de Jovens e Adultos integrada à Educação Profissional: identidades dos sujeitos, currículo integrado, mundo do trabalho e ambientes/ midias virtuais, financiada pelo Obeduc/Capes.

Com a implantação do Proeja, a partir do Decreto no 5.478/2005, nos Institutos Federais em todo o Brasil, verificou-se que no IFMT tal implantação não ocorreu em todos os campi, conforme Relatório de Gestão (IFMT, 2014) e Plano de Desenvolvimento Institucional (IFMT, 2014). O afastamento temporário ou permanente dos educandos nos cursos de Proeja ofertados nos campi do IFMT tem se elevado e devido a este motivo, muitos cursos foram extintos e os campi passaram a não mais ofertar a modalidade, como é o caso do curso investigado, cuja oferta de novas turmas foi suspensa em 2016/1.

Diante do exposto, este estudo se justifica por permitir um (re)pensar do Proeja no IFMT - Campus Várzea Grande e contribuir para a efetivação dessa política pública em todos os campi do IFMT. E ainda que haja diversos condicionantes - políticos, socioeconômicos, culturais e educacionais -, os quais convergem e influenciam para a elevação da evasão, questionou-se: Quais e como os elementos vivenciados na experiência do Curso Técnico em Serviços de Condomínio - Proeja do IFMT Campus Várzea Grande, contribuíram para a permanência/não permanência dos educandos do curso?

Esta pesquisa elegeu como metodologia o estudo de caso. A coleta de dados foi realizada com o uso de revisão bibliográfica, questionário, entrevistas, análise documental e observação em sala de aula. Os registros da observação, diálogos com o professor e educandos foram realizados em caderno de campo. A entrevista semiestruturada com o professor aconteceu após o término das observações, no sentido de apreendermos elementos que não foram possíveis de serem coletados na observação e por meio dos diálogos estabelecidos. A análise dos dados ocorreu com o cotejamento utilizando referenciais de Fri- 
gotto, Ciavatta e Ramos (2005), e as concepções e princípios delineados no Documento Base (2007) do Proeja, que também foram norteadores para a observação da prática do professor.

As pesquisas relativas ao Proeja no IFMT na modalidade e esta indicam que os problemas são idênticos nos diferentes campi do IFMT. Os resultados desta pesquisa evidenciaram lacunas em relação à oferta do Proeja no Campus Várzea Grande, que não se resumem apenas às práticas pedagógicas dos professores, que contribuíram para a situação final das matrículas no curso em 2017/2, com 28 alunos afastados e 9 alunos concluintes, como: critérios inadequados para a escolha do curso; elaboração do Projeto Pedagógico do Curso sem a participação dos professores do campus; inexistência de um trabalho de divulgação permanente do curso; processo seletivo que se embasou em critérios que náo atendem à realidade do sujeito da EJA; falta de formação inicial e continuada dos educadores para atuar no Proeja e ausência de práticas de planejamento coletivo. Neste texto, daremos ênfase na observação da prática pedagógica do professor do Proeja.

\section{Os limites e as possibilidades em torno da prática pedagógica no Proeja Campus Várzea Grande}

O plano de ensino é um documento que eu deixava pronto, entregava na direção, considerando como foco central a resolução de problema, mas acabava que na prática, no meu dia a dia eu modificava algumas coisas, porque na dinâmica de trabalho nem sempre as coisas acontecem exatamente como a gente coloca no papel. Entâo, de acordo com os acontecimentos, com os fatos e com minha lida com eles eu acabava enfeitando ainda mais o paváo, porque eles precisam de coisas dessa natureza, quanto mais beleza fizermos por eles, mais a gente acaba motivando. (Entrevista, P4, 20/03/2017, grifo nosso).

A observação da prática pedagógica em sala de aula se deu com o professor P10, que permitiu a observação e o acesso aos materiais utilizados nas aulas. Este professor tem formação específica em nível de especialização em Proeja, e consideramos que ele desenvolveria uma prática pedagógica que assumisse 
a EJA enquanto campo de conhecimento específico, a partir das necessidades dos alunos e reconhecesse o seu papel na EJA.

Concebemos que a prática pedagógica dos professores está intimamente ligada às suas concepções de homem, educação, sociedade e norteiam o seu fazer-pensar, sendo por sua vez, orientada pelas condiçóes sócio-econômicas e culturais do contexto em que estão inseridos. Procurando elaborar a sua concepção de mundo, de maneira crítica, coerente e consciente, pensando e escolhendo as formas de agir metodologicamente, participando enquanto sujeito na produção da história da humanidade, refletindo sobre ela, sendo guia de si mesmo - e não apenas guiado pelo exterior - tendo a marca da própria personalidade, sendo um intelectual orgânico das massas, o professor pode constituir uma 'práxis pedagógica'. Não uma prática qualquer, mas uma "práxis", na qual se obtém, pela crítica a concepção de mundo da qual faz parte, a clareza da concepção teórica subjacente à sua prática, ou seja, aquela que efetivamente embasa seu fazer pedagógico. (RODRIGUES, 2000, p. 171).

O professor observado ministrou uma disciplina no início do Curso Técnico em Serviços de Condomínio - Proeja em 2015/1, quando ingressaram na referida turma 30 alunos. Três anos depois, em 2017/2, no $6^{\circ}$ e último semestre do curso, este professor assumiu outra disciplina, com os alunos que concluíram o curso. A observação em sala de aula deu-se no $2^{\circ}$ bimestre letivo de 2017/2 (out. a nov.). A disciplina observada tem uma carga horária de 68 horas, com quatro aulas semanais, distribuídas em um dia da semana, das $18 \mathrm{~h} 50$ às $22 \mathrm{~h} 25$, e intervalo de 15 minutos.

Durante o período de observação da prática pedagógica em sala de aula, não foi realizada nenhuma reunião com o coordenador de curso e/ou o grupo de professores responsáveis pelas outras disciplinas do semestre, sendo este um dos fatores que dificultaram a efetivação da proposta do currículo integrado e da implantação e continuidade do Programa nos Institutos Federais (IF), dentre outros já constatados em nossa pesquisa e conforme apontado por Moura e Pinheiro (2009, p. 98): 
[...] a falta de processos sistemáticos de formação continuada dos docentes; a ausência de discussôes mais qualificadas no interior das instituiçóes acerca da concepção do EMI e da implantaçáo do Programa; a forma impositiva como esse Programa entrou em vigor; os elevados índices de evasão; e uma visão elitista de parte dos profissionais que integram a rede federal, os quais vinculam a entrada do público da EJA, nessas instituiçóes, a uma ameaça à qualidade do ensino ali existente. Dessa forma, esse conjunto de fatores contribui significativamente para que haja uma parcial rejeição ao Programa no interior da rede, reforçando a visão preconceituosa em direção aos seus sujeitos. Evidentemente, esses aspectos têm estreita relação com a construção e o desenvolvimento do currículo nessas instituiçóes.

Os fatores enumerados na citação acima se fizeram presentes nas falas dos dez professores entrevistados nesta pesquisa, e ao analisar a prática pedagógica observada cotejamos com o discurso dos professores entrevistados. Ao longo das observaçóes, foi possível constatar que, embora houvesse a previsão das aulas para iniciar às $18 \mathrm{~h} 50$, na prática elas só iniciavam às $19 \mathrm{~h}$, a fim de que o maior número de educandos pudesse chegar. Como forma de situar os educandos quanto ao conteúdo em estudo, em todas as aulas o professor realizava a revisão anterior, sendo perceptível que existia por parte deste a preocupação com quem faltou e perdeu o conteúdo.

Foi possível perceber que os alunos tinham muita liberdade na sala de aula. Em uma das aulas o professor iniciou o conteúdo falando de "ecologia e sustentabilidade", favorecendo a interaçáo e a participação dos alunos ao explorar e contextualizar o conteúdo com exemplos advindos da realidade dos próprios alunos, além de utilizar imagens a partir do data-show, sendo este um recurso bastante utilizado em todas as suas aulas. Ao fazer uma breve introdução do conteúdo a ser desenvolvido, o professor explicou que iria apresentar um vídeo. À medida que iam assistindo ao vídeo, os educandos faziam anotaçóes e ao final o professor questionou em que momentos os educandos fizeram relação entre o vídeo e o conteúdo abordado na aula.

Cabe salientar que o conteúdo abordado foi ecologia e sustentabilidade. Contudo, um educando comentou um trecho do vídeo - a erosáo dos ecossistemas e economias locais promovem um fluxo de pessoas que se deslocam 
para as cidades à procura de empregos - e assim, trazendo para a sua realidade, relatou que profissionais de sua área de trabalho, construção civil, "tem que se sujeitar a trabalhar pela metade do preço, porque se ele não aceitar, outro aceita" (Registro Caderno de Campo, Educando 1, 11/10/2017).

Nesse sentido, o Documento Base (2007, p. 45) ressalta uma das características desse sujeito "são portadores de saberes produzidos no cotidiano e na prática laboral”. Percebe-se que o professor deu espaço para as observaçóes dos educandos, porém, retornou ao conteúdo proposto. $\mathrm{O}$ professor alertou para o fato de o vídeo se reportar à realidade dos Estados Unidos da América (EUA), contudo, salientou que o que acontece no meio ambiente, seja na China, nos EUA ou em qualquer outro país, afeta também o nosso país, e que o vídeo produzido em 2007 ainda é atual e alerta para o consumo consciente.

Em outra ocasiáo, ao desenvolver o conteúdo de genética, o filme trabalhado, denominado Gattaca - Experiência Genética, permitiu uma discussão acerca da divisão do trabalho: trabalho manual, destinado às pessoas sem material genético selecionado e gerado naturalmente a partir da relação sexual, consideradas inválidas para aquela sociedade. Em contraposição ao trabalho intelectual destinado às pessoas geradas geneticamente a partir de material selecionado para serem perfeitas, porém a discussão voltada para a realidade do mundo do trabalho não foi propiciada pelo professor, possibilidade aberta não só pelo filme, como pelas discussóes demandadas pelos próprios educandos, dada a realidade de vida deles. Todavia, o filme permitiu também a discussão de vários conteúdos da disciplina, com a conclusão dos conteúdos relativos ao segundo bimestre.

Nesse momento, o professor deixou de fazer uma discussão acerca do mundo do trabalho, conforme proposto pelo Documento Base (2007), e de propiciar a integração curricular, e estabelecer a relação entre educação profissional, ensino médio e EJA.

Portanto, o currículo integrado é uma possibilidade de inovar pedagogicamente na concepçáo de ensino médio, em resposta aos diferentes sujeitos sociais para os quais se destina, por meio de uma concepção que considera o mundo do trabalho e que leva em conta os mais diversos saberes produzidos em diferentes espaços sociais. Abandona-se a perspectiva estreita de formaçáo para o mercado de trabalho, para assumir a 


\section{formação integral dos sujeitos, como forma de compreender}

e se compreender no mundo. (BRASIL, 2007, p. 43, grifo do autor).

Em se tratando da última aula observada, a pesquisadora realizou uma reflexão com o professor, no sentido de compreender se ele considerou a possibilidade da integração de sua disciplina com as demais, considerando a amplitude da temática que ele havia trabalhado com foco específico na disciplina de biologia.

O professor afirmou não ter tal percepção quando do momento de elaboração do plano de ensino e destacou a importância do olhar do pedagogo da instituição e do acompanhamento deste profissional aos docentes, enfatizando a necessidade deste na sala de aula em parceria com os professores, já que o pedagogo possui um conhecimento amplo do planejamento de todos os componentes curriculares pertencentes ao curso. O professor P10 evidencia em sua fala um dos motivos pelo qual não se percebe a integração curricular em sala de aula, quando este se refere à elaboraçáo do plano de ensino da disciplina no campus.

Isso é com cada professor, cada docente faz da forma dele, então [...] Eu penso assim, que deveríamos talvez se encontrar, até conversar um pouco mais sobre os alunos, sobre o conteúdo, pra ver se está, se há uma conversa entre o meu conteúdo, com o conteúdo do outro professor. Mas isso não acontece, isso talvez seria o ideal, ou sei lá, perto do ideal, alguma coisa assim. Mas o planejamento fica a cargo de cada um, cada um planeja [...] Entrou na sala de aula, faz o trabalho e vai embora.

\section{Pesquisador: Há espaço para discutir e planejar coleti- vamente?}

[...] talvez até haja espaço, mas o que acontece é que os professores, às vezes, eles pensam assim, 'ah, o meu trabalho é esse, de tal hora a tal hora, e acabou a minha hora e eu vou embora mesmo' [...] Talvez seja esse o pensamento, talvez seja de alguns, mas eu acho que o espaço a gente cria [...] pode ir para um lugar diferente, ou pode ser aqui mesmo. Apesar de que o espaço 
físico da nossa instituição é muito pequeno, mas a gente cria. (Entrevista, P10, 11/12/2017).

Diferentemente da percepção de P4, o Plano de Ensino vai muito além do mero cumprimento de uma obrigação. Contudo, é possível perceber na fala do professor P10 elementos que reafirmam a ausência de encontros para o planejamento coletivo, ficando a cargo de cada professor a tarefa de planejar sua disciplina individualmente.

Neste cenário, o que pudemos constatar na prática em sala de aula foi a ausência de uma proposta interdisciplinar com as demais disciplinas do curso, e a respeito do trabalho como princípio educativo proposto por Frigotto, Ciavatta e Ramos (2005, p. 74), enquanto educando trabalhador da EJA, "que na maioria das vezes retornam à escola ou a um curso de qualificação motivadas pelas dificuldades enfrentadas no mundo do trabalho", e para atender a este sujeito:

Uma "nova” trajetória formativa não pode ser traçada linearmente por uma etapa de formação básica voltada para a compreensão geral da vida social e, depois, uma outra etapa que proporciona a instrumentalização para o exercício profissional. (p.74).

Ao discutirem os sentidos da integração entre EB e EP, Frigotto, Ciavatta e Ramos (2005, p. 74) ressaltam que:

Por essa razão, enquanto o princípio da integração educação básica e educação profissional tem, para jovens em idade escolar, um fundamento epistemológico, baseado na não dicotomia entre conhecimentos gerais e específicos, para os adultos trabalhadores esse princípio adquire também um fundamento existencial. Somente processos formativos integrados possibilitam o resgate do direito à educação básica simultaneamente à qualificação profissional, devido às condições concretas de vida desses sujeitos, que não admitem a permanência prolongada em processos educativos formais, sem que tal experiência tenha sentido e significado face às suas necessidades subjetivas e sociais. 
O professor da EJA também precisa de muita sensibilidade e deve estar atento às necessidades do educando desta modalidade, no sentido de compreender seus contextos sociais, que perpassa pela apreensão desse sujeito em sua amplitude e complexidade. Pudemos constatar em vários momentos que o professor tem percepção quanto à realidade vivenciada pelos educandos.

Em uma das aulas o professor trabalhou a partir do vídeo "O micromundo dos artrópodes”, estabeleceu relação com o conteúdo que estava sendo abordado, além de permitir o questionamento e a discussão sobre o tema e, ao final, fez um fechamento do assunto para dirimir as dúvidas dos educandos. Como os educandos optaram por não ter intervalo, a aula encerrou às $21 \mathrm{~h} 45$ para facilitar àqueles que necessitavam pegar ônibus para voltar para casa, pois o Campus Várzea Grande fica em uma região periférica do município e só tem uma linha de transporte coletivo.

Em suas aulas, o professor sempre utiliza slides e o quadro ao mesmo tempo, o que favorece em muito a aprendizagem dos educandos, haja vista que o escrever no quadro possibilita respeitar o ritmo de leitura e escrita dos educandos, enquanto que utilizar somente os slides dificultaria o acompanhamento dos educandos mais lentos.

Em pesquisa com vinte alunos de um Curso Técnico em Proeja no IF Goiano, cujo objetivo buscou compreender, a partir da visão dos alunos, quais estratégias eram consideradas mais eficazes para a sua aprendizagem em aulas expositivas "quer seja ditada, copiada do quadro, exposta via projetor multimídia ou trabalho com texto, foi a forma de avaliar a turma em relaçáo à aceitação da exposição do conteúdo teórico" (FONSECA; OLIVEIRA; SANTANA, 2010, p. 135), os resultados da pesquisa evidenciaram que:

[...] percebeu-se que os estudantes de maior idade, de 31 a 45 anos, que foram um total de $35 \%$, demonstraram resistência em aceitar as aulas expositivas por meio do uso do projetor multimídia. [...] as aulas despertavam sonolência, pois havia muitas figuras e pouco texto [...] esses estudantes de maior idade demonstraram resistência e pouca habilidade em relaçâo a essa tecnologia. Os estudantes mais jovens, na faixa etária entre 18 e 21 anos, e com menos de quatro anos fora da escola, foram mais receptivos às aulas expositivas com o uso de projetor multimídia. Já os estudantes mais velhos preferiam aulas, na sala 
de aula, utilizando o quadro de giz [... que] torna a aula mais lenta, pois o estudante copia o conteúdo, para depois prestar atenção na explicação da professora. Com essa observação, pôde-se constatar também que os alunos de maior idade obtinham notas menores. [...] A estratégia mais aceita pelos estudantes foi a aula expositiva ditada. [...] a professora observou maior companheirismo entre os colegas, que se mantiveram unidos, além de anotarem todo o texto ditado. A aula ditada tinha suas pausas para explicaçóes do que foi ditado pela professora. (FONSECA; OLIVEIRA; SANTANA, 2010, p. 136-138).

As especificidades dos sujeitos educandos do Proeja vão além das estratégias que o professor precisa utilizar para garantir que a aprendizagem ocorra em sala de aula. Foi possível perceber que das $18 \mathrm{~h} 50$, quando inicia a aula, até por volta das $19 \mathrm{~h} 40$, a movimentação de chegada dos alunos é constante, pois os alunos do noturno, principalmente os do Proeja, chegam e entram a hora que podem, e para os alunos do turno diurno - do Ensino Médio Integrado regular -, a tolerância de atraso é de 15 minutos, náo sendo permitida a entrada do aluno após esse tempo, e ele precisa aguardar o início da próxima aula para a autorização de sua entrada em sala de aula. O Campus Várzea Grande em 2017/2 ofertou o Curso de Proeja - uma turma - motivo pelo qual algumas especificidades do público do noturno são consideradas, por se tratar de estudantes trabalhadores.

[...] o professor chega aqui, tem um grupo de trabalhadores que tem um monte de situação, que é diferente de você passar o conteúdo para o adolescente, que o adolescente praticamente está para estudar, ele está ali, esse é o trabalho dele, é estudar. Enquanto que os adultos, eles têm outros afazeres, têm filhos, têm trabalho, têm seus problemas de pagamento de dívidas e tudo mais, entáo eles vêm com um monte de carga um pouco mais pesada. E aí às vezes chega na sala de aula e a escola não contribui com aquilo, com a realidade deles. Eles querem alguma coisa dentro da realidade, às vezes, isso faz com que eles vão se afastando e, às vezes, faltam uma vez, faltam duas vezes, depois não vêm mais. Acabam desistindo da escola. (Entrevista, P10, 11/12/2017). 
A fala do professor P10 denota a sua percepção acerca das especificidades do sujeito educando trabalhador da EJA e como este considera tal realidade em seu planejamento e em sua prática pedagógica na sala de aula. Tal iniciativa corrobora com o exposto no Documento Base (2007) ao se pensar que os sujeitos da EJA têm idade superior ou igual a 18 anos "com trajetória escolar descontínua, [... faz-se necessário] tomar uma referência, certamente, bem próxima da realidade de vida dos sujeitos da EJA" (BRASIL, 2007, p. 45).

Em uma aula, um aspecto que chamou atenção foi o fato de que, quando o professor percebia que os educandos apresentavam sinais de cansaço, estes eram liberados para irem ao banheiro e tomar água, como forma de recompor as energias. Para Fonseca, Oliveira e Santana (2010, p. 136-138), a postura do professor que atua no Proeja é enfatizada enquanto sujeito do processo.

A postura do professor, o carisma e a sensibilidade de saber entender os limites de cada aluno foram evidenciados por este estudo, que observou que o aprendizado decorre mais do encontro de indivíduos e da metodologia de ensino do professor do que da disciplina propriamente dita. Melhor dizendo, foi observado que, no Proeja, além da importância de lançar conteúdo durante as aulas, observar a assimilação do conteúdo torna-se um ponto de sucesso para o objetivo do curso.

Ao abordar o conteúdo da genética com ênfase na "Genética Mendeliana”, o professor falou sobre as informaçóes genéticas e a influência dos genes dominantes e recessivos na transmissão hereditária das características de um organismo a seus filhos. Trata-se de um conteúdo complexo, mas os educandos foram realizando associaçóes com exemplos na própria família.

Ao apresentar o conteúdo acerca da Primeira Lei de Mendel, o professor aplicou algumas atividades utilizando o Quadro de Punnet. Por se tratar de uma turma pequena, o professor chamou os educandos para resolverem a atividade no quadro e assim conduziu a explicaçáo do conteúdo e o esclarecimento das dúvidas dos educandos de modo que toda a turma participasse. Com isso, percebe-se que o professor realizou a avaliação no sentido de perceber se os educandos compreenderam o conteúdo, aproveitando para fazer as intervençóes necessárias. 
Ao ser indagado sobre os desafios e dificuldades vivenciados na implementação das práticas pedagógicas e demais aspectos do processo educativo, P10 explicita a relevância na elaboração de cada aula de forma a contemplar as especificidades do sujeito educando do Proeja, tornando a aula mais atrativa, significativa e procurando o envolvimento do educando com o conteúdo ministrado.

Então, desafios são muitos, é cotidiano, é diário. Então, eu tenho aula com eles na quarta-feira, no domingo eu já começo a preparar as aulas deles. Então, os desafios são grandes, com o Proeja é muito maior o desafio que com o pessoal do ensino médio, no caso da questáo de que eles por qualquer coisa eles não vêm mais. [...] Então, são desafios assim que eu me imponho, coloco isso pra mim, pra ver se as minhas aulas fluem, melhorem, procuro fazer com que eles vão ao quadro, que eles escrevam, que eles também participem. (Entrevista, P10, 11/12/2017).

Ao final de uma aula, uma educanda perguntou ao professor se o conteúdo que é desenvolvido no Proeja é o mesmo conteúdo que é trabalhado com os educandos do curso Integrado regular; e se o conteúdo que é abordado com os educandos do curso Integrado regular também é corrido. O professor explicou que, assim como o Proeja, o Ensino Médio Integrado regular tem um conteúdo a cumprir, porém, a carga horária do Integrado regular (2.400 horas de base comum) é bem maior que a carga horária a ser cumprida no Proeja (1.200 horas de base comum), conforme exposto nas Diretrizes Curriculares Nacionais para Educação Básica (2013, p. 240). Para o componente curricular observado percebe-se uma diferença acentuada na carga horária desenvolvida nos cursos do Ensino Médio Integrado regular (204h em dois semestres) e no Proeja (68h) ofertados no Campus.

As indagaçóes feitas pela educanda nos levaram a refletir acerca dos motivos presentes em tais questionamentos: a educanda estava fazendo comparação entre o conteúdo ministrado no Ensino Médio Integrado regular e no Proeja? Ou da carga horária entre as duas modalidades? Tais questionamentos poderiam indicar dificuldades de aprendizagem por parte da educanda?

Diante desta constatação, por meio de um diálogo informal com a educanda, buscamos identificar suas angústias, aspiraçôes e expectativas com 
relação aos questionamentos feitos ao professor. A educanda esclareceu sobre sua dificuldade em acompanhar a disciplina com a apresentação de um conteúdo a cada semana e acrescentou:

$\mathrm{Na}$ época em que eu estudei, o professor passava exercícios para a gente resolver, então a gente aprendia. Depois eu voltei a estudar e foi tudo muito rápido, eu fiz o ensino fundamental em um ano na EJA. Fiz o processo seletivo aqui no IFMT para o Ensino Médio, mas achava que nem ia ser chamada. (Registro Caderno de Campo, Educanda 2, 07/11/2017).

A situação apresentada pela educanda demonstrou a sua capacidade de autoavaliação e proporcionou ao professor um diagnóstico do processo de ensino-aprendizagem, sendo este um dos momentos de avaliação que não se resume apenas em provas.

[...] quando se trabalha com pessoas adultas, o professor precisa reconhecer que ele possui características diferentes do aluno do ensino médio regular, como habilidades e dificuldades no mundo em que vive. Isso faz com que ele traga consigo diferentes habilidades e dificuldades e, provavelmente, maior capacidade de reflexão sobre o conhecimento e sobre seus próprios processos de aprendizagem. (OLIVEIRA, 1999, p. 60 apud FONSECA; OLIVEIRA; SANTANA, 2010, p. 125).

Ao ser indagado sobre as facilidades encontradas no trabalho realizado com os educandos do Proeja, o professor P10 denota a sua percepção a respeito das especificidades do educando do Ensino Médio Integrado regular e do educando do Proeja.

Facilidades é o interesse deles, os alunos são interessados mesmo, qualquer coisa que você coloca no quadro eles estão escrevendo, mesmo que não está entendendo, mas eles escrevem porque eles querem ter no caderno. E isso é uma facilidade. $\mathrm{O}$ aluno, se você falar 'olha pessoal, naquela aula tal', aí eles vão lá no caderno e tem tudo anotadinho e se você colocar uma vírgula no canto 
do quadro, eles colocam isso no caderno. Diferente do ensino médio, que eles nem abrem o caderno, se você não falar com eles, eles não abrem o caderno. (Entrevista, P10, 11/12/2017).

Cabe ressaltar que, em muitas situaçóes em sala de aula, o educando do Proeja não se sente confortável para expressar suas dúvidas, suas dificuldades, como revela a pesquisa de Fonseca, Oliveira e Santana (2010, p. 134), ao enfatizar sobre o olhar atento do professor.

[...] cuidado que o professor deve ter com a apreensão do conteúdo pelo aluno deve-se também ao fato de a timidez ser bem constante entre os alunos do Proeja, justificada talvez pela diferença entre as idades dos estudantes. Observou-se que os estudantes mais velhos pensam que os mais jovens já apreenderam o conteúdo, no entanto, os estudantes mais jovens pensam que o mesmo ocorreu com os primeiros.

Analisando o histórico escolar da educanda apresentado no ato da matrícula no IFMT, observamos que ela concluiu o ensino fundamental na rede estadual, sendo submetida a processo de classificaçáo conforme a Resolução CEE/MT no 002/2009³ , e, de acordo com a Resolução CEE/MT no 005/2011, concluiu os nove anos do ensino fundamental em um ano, o que nos faz refletir sobre a fala da aluna ao afirmar "[...] depois eu voltei a estudar e foi tudo muito rápido, eu fiz o ensino fundamental em um ano na EJA".

Alguns autores ${ }^{4}$ discutem acerca da modalidade marcada pela oferta de uma educação aligeirada, que não garante uma formação plena do sujeito trabalhador. Não se pode afirmar que esta é uma prática da Secretaria de

3 Esta resolução define no artigo 65: “Classificação é o posicionamento do educando em etapa organizada sob a forma de série, ano, fase, período semestral, alternância, ciclo, período de estudo, grupo não seriado ou outra forma adotada pela escola".

4 Ventura e Rummert (2011, p. 72) enfatizam que: "as práticas assumidas por muitas secretarias de educação em nosso país, [...] ainda é profundamente marcada pela lógica do supletivo [...], deixando, por isso, de responder à realidade e características desses alunos", e pouco têm considerado as Diretrizes Curriculares Nacionais. 
Educação-MT5 ${ }^{5}$, sendo este apenas um caso identificado entre os nossos alunos do Proeja, o que requer estudo e pesquisa acerca do processo de classificação e reclassificação dos alunos.

Ao final do curso, somente nove alunos concluíram com aprovação. Dos nove alunos que finalizaram o Curso Técnico em Serviços de Condomínio Proeja no Campus Várzea Grande, oito concluíram o ensino fundamental na Rede Municipal e/ou Estadual em Mato Grosso. Destes, uma aluna concluiu o ensino fundamental através da EJA Projovem Urbano e cinco concluíram na modalidade EJA.

Por ser um estudo acerca da prática pedagógica do professor que atua no Proeja, esperava-se que tal prática estivesse embasada nas premissas do currículo integrado e nas especificidades da EB, da EP e da EJA.

Para Lottermann (2012, p. 99): “existem poucas certezas em relação ao Currículo Integrado, uma delas é a de que ele só é possível se acompanhado por permanente atividade de formação e planejamento", e esta pesquisa constatou a inexistência de políticas de formação continuada e a ausência de práticas pedagógicas que envolvam o planejamento coletivo, no Campus Várzea Grande, apesar de estes fatores estarem presentes no Documento Base (2007).

\section{Considerações finais}

Ao concluir esta investigação, evidenciamos os limites e as possibilidades em torno da prática pedagógica docente como elemento fundante da permanência e êxito dos educandos do Proeja no IFMT Campus Várzea Grande. Todavia, os fatores identificados não se resumem apenas às práticas pedagógicas dos professores, pois, desde a sua criação, percebeu-se a fragilidade no planejamento do Projeto Pedagógico do referido curso, que culminou com a falta de formação inicial e continuada dos profissionais que nele atuaram, nos três campos em que devem se integrar educação básica (EB), profissional (EP) e EJA, forjada no sentido pleno do termo: com apreensão dos princípios que norteiam o currículo integrado; e principalmente uma política que atenda aos anseios, necessidades e especificidades da EJA.

5 Bognar (2017) salienta que a Resolução CEE/MT no 005/2011 alterou o funcionamento e a organização da proposta pedagógica dos CEJAs, com redução da carga horária do trabalho pedagógico, o que ocasionou a redução da carga horária do educador e da formação em serviço, desconsiderando os interesses postulados pelo Fórum Permanente de Debates da EJA de Mato Grosso (FPDEJA/ MT) "O qual demonstrava a insatisfação de educadores e educandos da EJA" (p. 16). 
A prática pedagógica, com foco na educação do trabalhador para o mundo do trabalho, apontou: um educando trabalhador, que tem responsabilidades com o próprio sustento e de familiares; a necessidade de compreender as especificidades destes sujeitos da modalidade - questáo visual, o material didático pedagógico; o considerar os ritmos e níveis de aprendizagem diferenciados; a baixa autoestima dos educandos; a abertura ao diálogo e à escuta aos alunos; a articulação dos conhecimentos técnico-científicos com os cotidianos, dando sentido e significado aos conhecimentos trabalhados -, de propiciar a aprendizagem e a retomada dos conhecimentos quando os educandos náo puderam estar presentes ou não apreenderam aquele conteúdo. Porém, muito há que ser feito, uma vez que inexiste um projeto educativo coerente com as reais necessidades e realidade dos sujeitos da EJA no IFMT Campus Várzea Grande.

\section{REFERÊNCIAS}

BOGNAR, I. O Percurso Formativo de Educadores de Jovens e Adultos em Colíder/ MT (1982 a 2009). 2017. 224 f. Dissertação (Mestrado em Educação) - Universidade Federal de Mato Grosso, Instituto de Educação, Programa de Pós-Graduação em Educação. Cuiabá, 2017.

BRASIL. MEC/SEB. Diretrizes Curriculares Nacionais Gerais da Educação Básica/ Ministério da Educaçáa. Secretaria de Educação Básica. Diretoria de Currículos e Educação Integral. Brasília: MEC, SEB, DICEI, 2013.

. MEC/SETEC. Documento Base. Programa Nacional de Integração da Educação Profissional com a Educação Básica na Modalidade de Educação de Jovens e Adultos, 2007. FONSECA, C. A.; OLIVEIRA, J. de F. A. C.; SANTANA, L. E. A busca de uma aprendizagem significativa para alunos do Proeja: estratégias adotadas no curso Técnico em Agroindústria do IF Goiano campus Morrinhos. 2010. In: MACHADO, M. M.; OLIVEIRA, J. F de (Orgs.). A formaçáo integrada do trabalhador: desafios de um campo em construção. São Paulo: Xamã, 2010.

FRIGOTTO, G.; CIAVATTA, M.; RAMOS, M. O trabalho como princípio educativo no projeto de educaçáo integral do trabalhador. $1^{\text {a }}$ Conferência Municipal de Educaçáo de Contagem, 2005. Disponível em: <http://www.contagem.mg.gov.br/arquivos/pdf/caderno_conferencia.pdf>.Acesso em: 10 jan. 2016.

MATO GROSSO. CEE/MT. Resoluçáo no 002/2009-CEE/MT. Estabelece normas aplicáveis para a Educação Básica no Sistema Estadual de Ensino e dá outras providências.

. CEE/MT. Resoluçáo no 005/2011-CEE/MT. Fixa normas para a oferta da Educação Básica na modalidade Educação de Jovens e Adultos no Sistema Estadual de Ensino. 
MOURA, D. H.; PINHEIRO, R. A. Currículo e formação humana no ensino médio técnico integrado de jovens e adultos. Em Aberto, v. 22, n. 82. Brasília: Instituto Nacional de Estudos e Pesquisas Educacionais Anísio Teixeira, nov. 2009, p. 91-108.

RODRIGUES, M. E. C. A Prática do Professor na Educaçáo de Adolescentes, Jovens e Adultos: a experiência do Projeto AJA de Goiânia-GO. 2000. 250f. Dissertaçáo (Mestrado em Educação)- Faculdade de Educação, Universidade Federal de Goiás, Goiânia, GO, 2000.

VENTURA, J.; RUMMERT T. S. Consideraçóes político-pedagógicas sobre as especificidades da Educação de jovens e adultos trabalhadores. In: SOUZA, J. dos S.; SALES, S. R. (Orgs.). Educaçáo de jovens e adultos: políticas e práticas educativas. Rio de Janeiro: NAU Editora, EDUR, 2011. 